\title{
Frequency and severity of irritable bowel syndrome in cigarette smokers
}

\author{
Melike Mercan Başpinar ${ }^{1}$ and Okcan Basat ${ }^{2}$ \\ ${ }^{1}$ Gaziosmanpaşa Taksim Eğitim ve Araştırma Hastanesi \\ ${ }^{2}$ Affiliation not available
}

May 22, 2021

\begin{abstract}
Background: Cigarette smoking has recently been associated with several gastrointestinal symptoms, and smoking cessation has been recommended as a life style change strategy for irritable bowel syndrome (IBS). This study assessed the prevalence of IBS in cigarette smokers based on the Rome IV criteria, the severity of nicotine dependence, and the effect of smoking cessation in IBS $(+)$ smokers. Method: This prospective study included 371 smokers who attended for smoking cessation treatment at family medicine clinics in a tertiary hospital between January and April 2019. Data on demographic characteristics, IBS status according to the Rome IV criteria, and Fagerstrom Test for Nicotine Dependence (FTND) scores were collected during face-to-face interviews. Results: The mean patient age was $40.7 \pm 11.96$ years, $29.4 \%$ were heavy smokers, and $18.1 \%$ had IBS. There was no relationship between the presence of IBS and the nicotine dependence level; however, there was a significant difference in age $(\mathrm{P}=0.03)$, duration of smoking ( $\mathrm{P}=0.05)$, FTND score $(\mathrm{P}=0.02)$, and sex $(\mathrm{P}<0.001)$ between those with and without IBS. Logistic regression analyses identified female sex to be a predictor of IBS in smokers (adjusted odds ratio $1.78,95 \%$ confidence interval 1.18-2.69; $\mathrm{P}=0.006)$. At the one-year follow-up, IBS $(+)$ smokers who had quit smoking showed a decrease in gastrointestinal symptoms $(\mathrm{P}=0.035)$. Conclusions: There was no association between severity of nicotine dependence and IBS, although the FTND score was higher in IBS(+) smokers than in IBS(-) smokers. Smoking cessation ameliorated gastrointestinal symptoms but had no effect on IBS status. Key words: irritable bowel syndrome, nicotine dependence, Rome IV criteria, smoking
\end{abstract}

\section{Hosted file}

ijcp_-tam_metin tablo \selectlanguage\{polish\}ş\selectlanguage\{english\}ekil_ - Kopya.docx available at https://authorea.com/users/415150/articles/523050-frequency-and-severity-ofirritable-bowel-syndrome-in-cigarette-smokers 